\title{
Parasite distribution and associated immune response during the acute phase of Toxoplasma gondii infection in sheep
}

\author{
Delfien Verhelst ${ }^{*}$, Stphane De Craeye ${ }^{2}$, Gary Entrican ${ }^{3}$, Pierre Dorny ${ }^{4,5}$ and Eric Cox ${ }^{1}$
}

\begin{abstract}
Background: In many countries, Toxoplasma gondii (T. gondii) is a major cause of reproductive disorders and abortions in the sheep industry, and therefore responsible for important financial and economic losses. In addition, undercooked infected lamb is an important risk factor for human toxoplasmosis.

In the present study, the initial phase of the infection was investigated: the parasite s entry site, the subsequent distribution of the parasite and the host-immune response.

Results: Parasite DNA was already detected in the cranial small intestinal mucosa the first days after oral infection with T. gondii tissue cysts. Simultaneously, high IFN-gamma and IL-12 responses were induced mainly in the mesenteric lymph nodes. The emergence of IgG1 (at 8dpi), and IgG2 (at $11 \mathrm{dpi}$ ) was accompanied by a decrease or even disappearance of the IFN-gamma and IL-12 response in the Peyers patches (PP), PBMC s and popliteal LN s. Meanwhile the parasite DNA could be recovered from most mucosal and systemic tissues to become undetectable in the small intestine, popliteal LN, PBMC and spleen 3 weeks pi.

Conclusions: Our results indicate that parasites enter the cranial small intestine the first days after infection and that after an increase the first two weeks after infection, the parasite DNA levels in the intestine drop below the detection limit three weeks after infection. This coincides with an increase in parastic-specific serum $\lg G 1$ and $\lg G 2$ and a decrease of the antigen-specific IFN-gamma response in PP, PBMC and popliteal LN. We suggest a role for IFN-gamma and IL-12 in controlling the infection.
\end{abstract}

Keywords: Toxoplasma gondii, Immune responses, Quantitative PCR, ELISA, Sheep

\section{Background}

Toxoplasma gondii is an obligate intracellular parasite with a worldwide prevalence in a wide variety of hosts [1]. In many countries, the parasite is a major cause of reproductive disorders, miscarriages and abortions in the sheep industry, and therefore responsible for important financial and economic losses [2,3]. Based on data collected by the Veterinary Investigation Diagnosis Analysis in 2009 [4], toxoplasmosis is the second cause of abortions in sheep in the UK after Chlamydia abortus (45.6\%).

Undercooked infected lamb is considered as an important risk factor for human toxoplasmosis [5]. Infection of herbivorous animals occurs mostly through ingestion of

\footnotetext{
* Correspondence: Delfien.verhelst@ugent.be

'Laboratory of Immunology, Faculty of Veterinary Medicine, Ghent University, Ghent, Belgium

Full list of author information is available at the end of the article
}

T. gondii oocysts excreted by cats. One week after a first infection, cats can shed over 100 million oocysts in their faeces during a period of 714 days depending on the infection dose, the infection stage and the immune status of the cat. Sporulated oocysts can stay infectious in the environment during more than 1 year and contaminate pastures, feeds and also drinking water $[6,7]$.

An acute primary infection during gestation will result in transmission of the parasite to the foetus. As in humans, the consequences for the foetus depend on the stage of the gestation: an early infection (during the first or second trimester of gestation) results in fetal death and resorption or abortion, whereas a later infection leads to the birth of clinically normal but latently infected lambs or of lambs with symptoms of congenital toxoplasmosis (fever, growth retardation, weakness) [8-10].

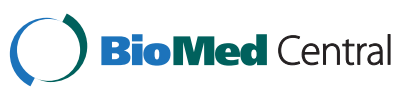

2014 Verhelst et al.; licensee BioMed Central. This is an Open Access article distributed under the terms of the Creative Commons Attribution License (http://creativecommons.org/licenses/by/4.0), which permits unrestricted use, distribution, and reproduction in any medium, provided the original work is properly credited. The Creative Commons Public Domain Dedication waiver (http://creativecommons.org/publicdomain/zero/1.0/) applies to the data made available in this article, unless otherwise stated. 
The immunity developed by the pregnant ewe will protect it against infection of the foeti during subsequent gestations [7]. The same protection seems to occur when a non-pregnant ewe becomes infected with T. gondii $[10,11]$. Data of Morley et al. [12,13] suggested that immunity might protect less well against transplacental transmission than thought. However, their studies were based on $T$. gondii DNA detection only and not on demonstration of $T$. gondii-associated lesions by histopathology, nor did they exclude other abortifacient agents [14]. Williams et al. [15] suggest that the observations of Morley et al. [12,13] are due to breed differences. Furthermore, the effectiveness of vaccination with Toxo-Vax is mentioned in several studies [16-18].

Whereas several experimental infections have been carried out in sheep to study host-immune responses, to our knowledge, the distribution of the parasite and the correlated antibody and interferon (IFN)-gamma responses during acute ovine toxoplasmosis have not been studied yet $[2,7,14,19-21]$.

In the present study, oral infections of sheep with $T$. gondii tissue cysts were performed to determine the entry site and subsequent distribution of the parasite following the natural infection route. Furthermore, we monitored the local IFN-gamma response during the acute phase of the infection, because of its important role as a mediator of host resistance against Toxoplasma as demonstrated in mice, sheep and humans [17,22,23].

\section{Methods}

\section{Animals and experimental procedure}

Thirteen 7-week-old conventionally reared lambs were selected (Belgian cross-breed, Zootechnical Centre, Leuven, Belgium), based on their T. gondii and Neospora caninum seronegative status. The absence of antibodies against $T$. gondii was assessed by an indirect immunofluorescence assay (IFA, Toxo-Spot IF, Biomrieux, Marcy-l Etoile, France). As anti-Neospora antibodies could cross-react with $T$. gondii antigens, the sera were also tested with the Neospora caninum Antibody Test Kit (CHEKIT* Neospora, Idexx, Hoofdorp, The Netherlands).

After an acclimation period of one week at the experimental animal facilities of Ghent University, eleven animals were orally infected with 3000 tissue cysts of the $T$. gondii Prugniaud strain (PRU). PRU is a type II genotype isolated from a case of human lethal congenital toxoplasmosis $[24,25]$. Sheep were killed by captive bolt and exsanguination on day 4 ( $4 \mathrm{dpi} ; \mathrm{N}=3), 8$ ( $8 \mathrm{dpi} ; \mathrm{N}=2), 10$ (10 dpi; $\mathrm{N}=2), 14$ (14 dpi; $\mathrm{N}=1$ ) and 21 (21 dpi; $\mathrm{N}=3$ ) after infection. Two animals were kept as negative controls $(\mathrm{C})$ and euthanized at 21 days. Blood samples were taken daily from the jugular vein of each animal until euthanasia for monitoring the $T$. gondii-specific serum antibody response. At euthanasia, portions of duodenal (D), jejunal
(J) and ileal (I) tissue with and without Peyers patches (PP), the draining mesenteric lymph nodes (MLN), popliteal lymph nodes, spleen and blood on heparin were sampled. Samples were processed as described further to determine the spread of the parasite as well as the appearance of a specific IFN-gamma response in the different tissues at the early phase of the infection.

All experimental and animal management procedures were approved by the Animal Care and Ethics Committee of the faculties of Bioscience Engineering and Veterinary Medicine, Ghent University (2007/103).

\section{Inoculum}

Tissue cysts of the $T$. gondii PRU strain were harvested from the brains of chronically infected C57BL6 mice and quantified as described by Verhelst et al. [26]. Briefly, infected mice were euthanized five weeks after infection and their brains were homogenized in phosphate buffered saline (PBS) using a Potter Homogenizer. The concentration of brain cysts in the suspension was determined by phase contrast microscopy whereafter the brain homogenate was diluted in PBS to obtain a final concentration of 300 cysts per $\mathrm{ml}$. The sham inoculate given to the control animals was prepared similarly from brains of non-infected mice.

\section{Purification of recombinant antigens}

The recombinant antigens GRA7, EC2 and $\mathrm{MIC}_{234} 307$ were used to stimulate cell suspensions for IFN-gamma and IL-12 production. GRA7 has already been demonstrated to be useful as a sero-diagnostic marker of acute and chronic toxoplasmosis [27-29]. Furthermore GRA7 is expressed by all infectious stages of $T$. gondii and appears plentiful on the surface of the host cells, the host cell cytosol, the parasitophorous vacuolar membrane and lumen [30]. After rupture of the host cells, high amounts of GRA7 come in contact with the host immune system, triggering strong antibody responses [31]. The recombinant EC2 antigen is a chimer of the antigenic regions of the microneme proteins $\mathrm{MIC2}$ and MIC3 and of the surface antigen SAG1.

The recombinant antigens were produced as previously described [26,32]. Briefly, the HIS-tagged recombinant antigens were purified from an $E$. coli culture using metal chelate affinity chromatography (Ni-NTA Superflow, Qiagen, GmbH, Hilden, Germany), according to the manufacturers instructions. The recombinant antigens were eluted from the Ni-NTA columns by incubation in $500 \mathrm{mM}$ imidazol buffer followed by dialysis through a CelluSep H1 membrane with a $8 \mathrm{kDa}$ cut-off (Membrane Filtration Products, Texas, USA) in urea buffer for EC2 and GRA7 and in PBS for MIC3 3234 307.

Toxoplasma total lysate antigen (TLA) was produced as described before [33]. Briefly, $T$. gondii RH tachyzoites (type I strain) were harvested from the peritoneal cavity 
of Swiss mice, which had been intraperitoneally infected 4 days earlier. Hereto, collected ascites fluid was passed twice through a 26-gauge needle. After centrifugation for 15 minutes at $950 \mathrm{~g}$, the pellet containing the tachyzoites was washed twice in PBS, followed by sonication in an Ultrasonic disintegrator (MSE, Leicester, United Kingdom) to solubilize the T. gondii tachyzoite antigens. The total protein concentration was measured by the bicinchoninic acid (BCA) reaction (Thermo Scientific Pierce BCA Protein Assay Kit), whereafter the antigen suspension was aliquoted and stored at $-20 \mathrm{C}$ until use.

\section{Indirect Immunofluorescence Assay (IFA)}

To test for the presence of specific IgG and IgM antibodies against $T$. gondii; the sheep sera were diluted 1:50 in PBS and tested as follows: fifty microliter of this dilution was applied on a slide coated with formalintreated T. gondii RH tachyzoites (Toxo-Spot IF, Biomrieux, Marcy-l Etoile, France) for $30 \mathrm{~min}$ at $37 \mathrm{C}$. On each slide, seronegative and seropositive sheep reference serum samples were used as controls. After washing with PBS, $30 \mu \mathrm{l}$ of a 1:25 in PBS-Evans Blue diluted fluorescein isothiocyanate conjugated rabbit anti-sheep IgM or rabbit antisheep IgG (KPL, Maryland, USA) was applied for 30 minutes at $37 \mathrm{C}$. The slides were then washed again, airdried and read using a fluorescence microscope.

\section{T. gondii -specific antibody ELISA}

The presence of $T$. gondii antigen-specific IgG, IgG1, IgG2 and IgA in the collected sera was tested by ELISA. Nunc maxisorp immunoplates (Life Technologies, Merelbeke, Belgium) were coated overnight at $4 \mathrm{C}$ with TLA at a concentration of $10 \mu \mathrm{g} / \mathrm{ml}$ in bicarbonate coating buffer (pH 9.7). In subsequent steps, the plates were blocked during 2 hours at $37 \mathrm{C}$ in $1 \%$ non-fat milk powder in PBS, incubated for $1 \mathrm{~h}$ at $37 \mathrm{C}$ with 100 -fold diluted sera in PBS with $0.05 \%$ Tween 20 and $1 \%$ non-fat milk powder. This was followed by an incubation step for $1 \mathrm{~h}$ at $37 \mathrm{C}$ with rabbit anti-sheep IgG- or IgA-labelled with horseradish peroxidase (AbD Serotec (Gentaur), Brussels, Belgium); or with a mouse anti-bovine IgG1 or IgG2 secondary antibody followed by an incubation with an anti-mouse immunoglobulin-horseradish peroxidase conjugate. Subsequently a $3,3^{\prime}, 5,5^{\prime}$-tetramethylbenzidine solution (TMB) (Sigma Aldrich, Diegem, Belgium) was added. In between each step, plates were manually washed 5 times with PBS $0.05 \%$ Tween 20 . The reaction was stopped by adding $50 \mu \mathrm{l} 2 \mathrm{M} \mathrm{H}_{2} \mathrm{SO}_{4}$ (stop solution). Absorbance was read at $450 \mathrm{~nm}$. Positive and negative control sera were included on each plate. The corrected optical density (OD) was calculated as: OD of sample OD of negative control sample. The serum samples were considered positive when the corrected optical density $\left(\mathrm{OD}_{450}\right)$ of the dilutions exceeded the cut-off value $\left(=\right.$ mean $\mathrm{OD}_{450}$ (negative controls) +3 its standard deviation). The negative control sera in the IFA and ELISA were from $T$. gondii negative sheep. They tested negative in the Modified Agglutination test, the IFA and the Sabin Feldman Dye Test.

\section{Isolation of mononuclear cells (MCs) from blood, spleen, lymph nodes and intestine}

The MCs from blood and spleen were isolated as described by Verhelst et al. [26]. The peripheral blood MCs (PBMCs) were isolated by density gradient centrifugation using Lymphoprep (Nycomed, Brussels, Belgium). Briefly, heparinized blood was centrifuged during $25 \mathrm{~min}$ at $1000 \mathrm{~g}$ and 18C. After removing the plasma layer, the buffy coat and erythrocyte pellet were suspended in an equal volume of PBS with $1 \mathrm{mM}$ ethylediaminetetraacetic acid (PBS-EDTA) and layered onto the gradient. Tubes were centrifuged for $45 \mathrm{~min}$ at $800 \mathrm{~g}$ and $18 \mathrm{C}$. The interface layer, containing the MCs, was collected and the cells were washed in PBS-EDTA.

Splenocytes were isolated from the spleen after removing the surrounding fat. The obtained cell suspension was further purified by lysing the erythrocytes in the presence of ammonium chloride. After centrifugation (380 $\mathrm{g}$ at $18 \mathrm{C}$ for $10 \mathrm{~min}$ ), the pelleted cells were washed and resuspended in PBS-EDTA $(1 \mathrm{mM})$.

The MCs from mesenteric lymph nodes (MLN), popliteal LN, duodenal, jejunal and ilial Peyers Patches (PP) were isolated as described by Vandenbroeck et al. [34] and the MCs from the duodenal, jejunal and ileal lamina propria as described by Vande Walle et al. [35]. All isolated cells were resuspended at a final concentration of $1 \quad 10^{7}$ cells $/ \mathrm{ml}$ in complete leucocyte medium (RPMI 1640, Gibco, Merelbeke, Belgium) supplemented with $10 \%$ fetal calf serum (FCS, Greiner Bio-One, Belgium), $200 \mathrm{mML}$-glutamin (Gibco), $100 \mathrm{U} / \mathrm{ml}$ penicillin and $100 \mu \mathrm{g} / \mathrm{ml}$ streptomycin (P/S; Gibco), $100 \mathrm{mM}$ nonessential amino acids (Gibco) and $100 \mu \mathrm{g} / \mathrm{ml}$ kanamycin (Gibco).

\section{Isolation of enterocytes from the intestine}

At euthanasia, duodenal, jejunal and ileal segments without PP of approximately one meter were sampled, flushed three times with Krebs buffer $(0.12 \mathrm{M} \mathrm{NaCl}$, $0.014 \mathrm{M} \mathrm{KCl}, 0.001 \mathrm{M} \mathrm{KH}_{2} \mathrm{PO}_{4}, 0.025 \mathrm{M} \mathrm{NaHCO}_{3}$, $\mathrm{pH}$ 7.4) at room temperature and filled for $95 \%$ with Hank s Buffered Salt Solution (HBSS) supplemented with $1.5 \mathrm{mM}$ EDTA +1 mM 1,4-dithiothreitol (DTT) preheated at $37 \mathrm{C}$. Then the segments were incubated in 2 liter PBS for $15 \mathrm{~min}$ at $37 \mathrm{C}$. Thereafter, the contents were collected and placed at $4 \mathrm{C}$. This process was repeated twice. The isolated cells were pooled and washed three times with HBSS supplemented with $0.1 \mathrm{mM}$ phenylmethylsulfonyl fluoride (PMSF). PMSF is a serine 
protease inhibitor that prevents proteolytic degradation of proteins [36]. After centrifugation for $10 \mathrm{~min}$ at $1800 \mathrm{~g}$ and $4 \mathrm{C}$, the cells were resuspended in complete medium at a concentration of $10^{7}$ cells $/ \mathrm{ml}$.

\section{Detection of parasite DNA in cell populations by real-time PCR}

DNA was extracted from cell suspensions using the Qiagen QIAmp DNA Mini kit (Qiagen GmbH, Hilden, Germany), according to the manufacturer s instructions. Next, the presence of $T$. gondii DNA was determined by duplex qPCR analysis as described before [37]: the $T$. gondii repeat element (AF146527) was used as target for the detection of the parasites DNA and the amplification of the cellular 18S rRNA gene Since host cells are always present in the sample, the latter reaction should always be positive. Tenfold dilutions of a counted number of $\mathrm{RH}$ tachyzoites and cultured swine kidney cells (SK-6) were used to generate a standard line for the quantification of T. gondii parasite DNA and one for the cells, respectively. Real-time PCR was performed with an initial $3 \mathrm{~min}$ denaturation step at $95 \mathrm{C}$, followed by 45 cycles at $95 \mathrm{C}$ for $15 \mathrm{sec}$ and $60 \mathrm{C}$ for $20 \mathrm{sec}$.

\section{Restimulation of isolated mononuclear cells with T. gondii antigens}

The MCs were seeded in 96-well flat bottom cell culture plates (Greiner bio-one) at $10^{6}$ cells/ per $100 \mu$ l complete medium and per well. After an initial incubation of $12 \mathrm{~h}$, the mitogen concanavalin A (Con A) $(5 \mu \mathrm{g} / \mathrm{ml})$ (BD Biosciences) or $10 \mu \mathrm{g} / \mathrm{ml}$ of one of the following antigens was added: rEC2, rGRA7, rMIC3 or, total lysate antigen (TLA). The recombinant proteins were diluted in complete medium, supplemented with $10 \mu \mathrm{g} / \mathrm{ml}$ polymyxin B to neutralize potentially contaminating endotoxin [38]. After a $6 \mathrm{~h}$ incubation at $37 \mathrm{C}$ in a humidified atmosphere with $5 \% \mathrm{CO}_{2}$ for Con $\mathrm{A}$ or $96 \mathrm{~h}$ for the antigens, the cell-free supernatant was removed and stored at -20C until analysed for interferon-gamma (IFN-gamma) concentration by ELISA.

\section{Cytokine ELISA}

To determine the IFN-gamma and interleukin 12 (IL-12) concentrations in the cell-free culture supernatants, 96well Nunc maxisorp immunoplates (Life Technologies) were coated overnight at $4 \mathrm{C}$ with a mouse anti-bovine IFN-gamma monoclonal antibody (mAb) (CC330; AbD Serotec) at $5 \mu \mathrm{g} / \mathrm{ml}$ or with a mouse anti-bovine IL-12 $\mathrm{mAb}$ at $2.5 \mu \mathrm{g} / \mathrm{ml}$ (CC301; AbD Serotec), respectively. Then, the plates were blocked for $2 \mathrm{~h}$ at room temperature (RT) with PBS containing 0.05\% Tween 20 and $3 \%$ non-fat milk powder. In subsequent steps we added each for $1 \mathrm{~h}$ at RT: $100 \mu \mathrm{l}$ of cell culture supernatant 1:2 in PBS supplemented with $0.05 \%$ Tween 20 and $1 \%$ non-fat milk powder, a biotin-labelled mouse anti-bovine IFN-gamma mAb (CC302b; AbD Serotec) or a biotin-labelled mouse anti-bovine IL-12 mAb (CC326; AbD Serotec) and horseradish peroxidase (HRP)conjugated streptavidin (Abd Serotec). In between each step, plates were washed 5 times with PBS supplemented with $0.05 \%$ Tween 20 . Then, a HRP substrate solution (3,3',5,5' -tetramethylbenzidine (TMB, Sigma Aldrich)) was added for $30 \mathrm{~min}$ at $\mathrm{RT}$ in the dark. The reaction was stopped by adding $50 \mu \mathrm{l} \mathrm{H}_{2} \mathrm{SO}_{4}(2 \mathrm{~N})$ and the optical density (OD) was measured at $450 \mathrm{~nm}$.

The IFN-gamma and IL-12 concentrations in the cell culture supernatants were calculated from a regression line using the DeltaSoft JV 2.1.2 software. The regression lines were obtained by including in the tests 10-fold dilutions of recombinant ovine IFN-gamma or IL-12 starting from $4000 \mathrm{pg} / \mathrm{ml}$ and $320 \mathrm{u} / \mathrm{ml}$, respectively. The recombinant ovine IFN-gamma and ovine IL-12 were prepared as a serum-free conditioned medium from transfected $\mathrm{CHO}$ cells, according to a protocol described for the production of recombinant ovine IL-4 [39]. The recombinant ovine IFN-gamma was quantified using the recombinant bovine IFN-gamma standard sold by Endogen, Thermo-scientific (Rockford, USA) and the anti-bovine mAbs clones CC330 and CC302b (AbD Serotec) in a species cross-reactive ELISA (personal communication with Sean Wattegedera, Moredun Research Institute).

\section{Results}

\section{Neospora caninum antibodies}

None of the control or experimentally infected animals showed IgG response against $N$. caninum at euthanasia.

\section{Presence of T. gondii in tissues}

The presence of $T$. gondii in the various tissues collected after euthanasia was evaluated by qPCR (Table 1). At 4 days post infection (dpi), parasite DNA could be found sporadically in tissues of two out of three sheep. These sheep had T. gondii DNA in their epithelium (enterocytes, lamina propria) and in the organized lymphoid tissue of the small intestine (PP) or draining the small intestine (MLN), mostly in the cranial parts. In one sheep the parasite could be detected in peripheral blood mononuclear cells (PBMC). In the third sheep, no $T$. gondii DNA was detected, suggesting that the parasite had not yet invaded the gut at this time point, had already left this site, or that the parasitic load was still below the detection limit. In the sheep analysed at $8 \mathrm{dpi}$, more tissues were found positive for $T$. gondii DNA. The epithelium and draining lymph nodes of both sheep were positive throughout the small intestine, the lamina propria and Peyers patches in the duodenum. Other parts of the small intestine, popliteal lymph nodes and spleen were positive in only one sheep. This presence in 
Table 1 Presence of parasite DNA in different small intestinal tissues, lymph nodes and blood of sheep orally infected with 3000 T. gondii PRU tachyzoites and euthanized at different days post infection (dpi)

\begin{tabular}{|c|c|c|c|c|c|c|c|c|c|c|c|c|}
\hline \multirow{3}{*}{ Time } & \multicolumn{12}{|c|}{ Parasite load as determined by RT qPCR and expressed as log 10 of parasite DNA/ $10^{6}$ cells } \\
\hline & \multirow{2}{*}{$\begin{array}{l}\text { DPI } \\
\text { Animals }\end{array}$} & \multicolumn{3}{|l|}{4} & \multicolumn{2}{|l|}{8} & \multicolumn{2}{|l|}{10} & \multirow{2}{*}{$\begin{array}{l}14 \\
\text { Sh8 }\end{array}$} & \multicolumn{3}{|l|}{21} \\
\hline & & Sh1 & Sh2 & Sh3 & Sh4 & Sh5 & Sh6 & Sh7 & & Sh9 & Sh10 & Sh11 \\
\hline \multicolumn{2}{|c|}{ Duodenal E } & 0,36 & nd & nd & 3,06 & $-2,26$ & $-3,06$ & $-2,23$ & $-2,90$ & nd & nd & nd \\
\hline \multicolumn{2}{|c|}{ Duodenal LP } & $-0,43$ & nd & nd & 2,88 & $-1,60$ & $-1,46$ & $-2,59$ & 2,74 & nd & nd & $-1,58$ \\
\hline \multicolumn{2}{|c|}{ Duodenal PP } & nd & 0,11 & nd & 2,26 & $-1,15$ & $-2,68$ & $-0,74$ & 4,09 & nd & nd & nd \\
\hline \multicolumn{2}{|c|}{ Jejunal E } & nd & nd & nd & 2,23 & $-0,64$ & nd & $-2,67$ & $-1,54$ & nd & nd & $-0,67$ \\
\hline \multicolumn{2}{|c|}{ Jejunal LP } & nd & nd & nd & nd & $-0,02$ & $-1,67$ & nd & $-1,96$ & nd & nd & nd \\
\hline \multicolumn{2}{|c|}{ Jejunal PP } & nd & nd & nd & nd & $-1,23$ & nd & $-2,07$ & 3,40 & nd & nd & nd \\
\hline \multicolumn{2}{|l|}{ Ileal E } & nd & $-0,16$ & nd & 0,87 & $-1,44$ & nd & $-3,29$ & $-1,86$ & nd & nd & nd \\
\hline \multicolumn{2}{|c|}{ Ileal LP } & nd & nd & nd & nd & $-0,44$ & $-1,91$ & $-4,00$ & $-2,10$ & nd & nd & nd \\
\hline \multicolumn{2}{|c|}{ Ileal PP } & nd & nd & nd & nd & $-2,00$ & nd & nd & 2,95 & nd & nd & nd \\
\hline \multicolumn{2}{|c|}{ Duodenal MLN } & 0,34 & nd & nd & 1,95 & $-0,31$ & $-1,20$ & $-0,77$ & 2,76 & 0,05 & nd & nd \\
\hline \multicolumn{2}{|c|}{ Jejunal MLN } & 2,63 & nd & nd & 1,45 & $-0,51$ & $-0,99$ & $-0,94$ & 3,67 & 8,37 & nd & nd \\
\hline \multicolumn{2}{|c|}{ Ileal MLN } & nd & nd & nd & 2,44 & $-0,72$ & $-2,87$ & $-1,06$ & 3,19 & $-1,29$ & nd & nd \\
\hline \multicolumn{2}{|c|}{ Peripheral blood MC } & 0,45 & nd & nd & nd & nd & nd & $-1,68$ & $-1,30$ & nd & nd & nd \\
\hline \multicolumn{2}{|c|}{ Popliteal LN } & nd & nd & nd & nd & $-1,54$ & $-1,66$ & $-0,89$ & nd & nd & nd & nd \\
\hline \multicolumn{2}{|c|}{ Splenocytes } & nd & nd & nd & nd & $-2,49$ & nd & $-2,00$ & nd & nd & nd & nd \\
\hline
\end{tabular}

$\mathrm{Sh}=$ Sheep. $\mathrm{E}=$ Enterocytes. $\mathrm{LP}=$ Lamina propria. $\mathrm{PP}=$ Peyers patches. MLN = Mesenteric lymph nodes. MC $=$ Mononuclear cells. $\mathrm{LN}=\mathrm{Lymph}$ node. $\mathrm{Nd}=$ Not detected

the systemic tissues indicates dissemination was occurring. At 10 dpi a similar pattern was seen for the intestinal tissues and MLN, but now both euthanized animals showed parasite DNA in their popliteal lymph nodes, confirming the dissemination observed in one sheep at day 8. At 14 dpi the only euthanized animal had parasite DNA in all its intestinal tissues with the highest amounts in the Peyers patches and MLN, whereas popliteal lymph nodes and spleen were negative. One week later (21 dpi), the parasite load had dropped below the detection limit in most tissues. In one animal only parasite DNA was demonstrated in its MLN with the highest amounts in jejunal MLN. The other animal had low levels of parasite DNA in its jejunal epithelium and duodenal lamina propria. The third sheep tested negative. This suggests that either most of the parasites had left the intestinal and lymphoid tissues or were cleared from these tissues at this time point.

When comparing the parasitic load in the tissues of the four animals euthanized at 8 and $10 \mathrm{dpi}$ a trend could be observed in cranial versus caudal intestinal tissues. For each of the four animals, one or more of the tested duodenal tissues or its associated draining lymph node, showed the highest or second highest amount of parasite DNA, while the tested ileal tissues often showed the lowest amount. In 5 of 12 ileal tissues samples even no parasite DNA could be detected at all. Overall the ileal Peyers patches showed the lowest amount of parasite DNA. These data suggest that shortly upon release from the cysts, the parasite invades the gut primarily in the cranial small intestine.

The two sham infected animals remained $T$. gondiifree in all tissues.

\section{Humoral immune response}

The kinetics of the antibody response after the oral infection was determined on sera collected daily. Both a Toxoplasma-specific IgM and IgG IFA as a TLA-specific IgG, IgG1, IgG2 and IgA ELISA were performed. Data of the TLA-specific IgG ELISA are presented in Figure 1.

Toxoplasma-specific IgM was first detected at 9, 12 and $15 \mathrm{dpi}$, in three of the then 6 non-euthanized sheep (3/6), two on 4 sheep (2/4) and two on 3 sheep (2/3), respectively. In one sheep no specific IgM could be detected until euthanasia at 3 weeks post infection. IgG was detected by IFA in one sheep at $9 \mathrm{dpi}(1 / 6)$ and in another sheep at $12 \mathrm{dpi}(1 / 4)$. These animals remained seropositive until euthanasia.

In ELISA, the $T$. gondii-specific IgG was detected first at $7,8,10$ and $15 \mathrm{dpi}$, each time in one animal and remained present in these animals until euthanasia. Interestingly, in one animal no TLA-specific IgG response was seen although parasite DNA could be detected in its tissues at euthanasia 21dpi. IgG1 appeared in one sheep $15 \mathrm{dpi}$ and in another sheep $17 \mathrm{dpi}$. IgG2 appeared in the same two animals, but slightly earlier, 


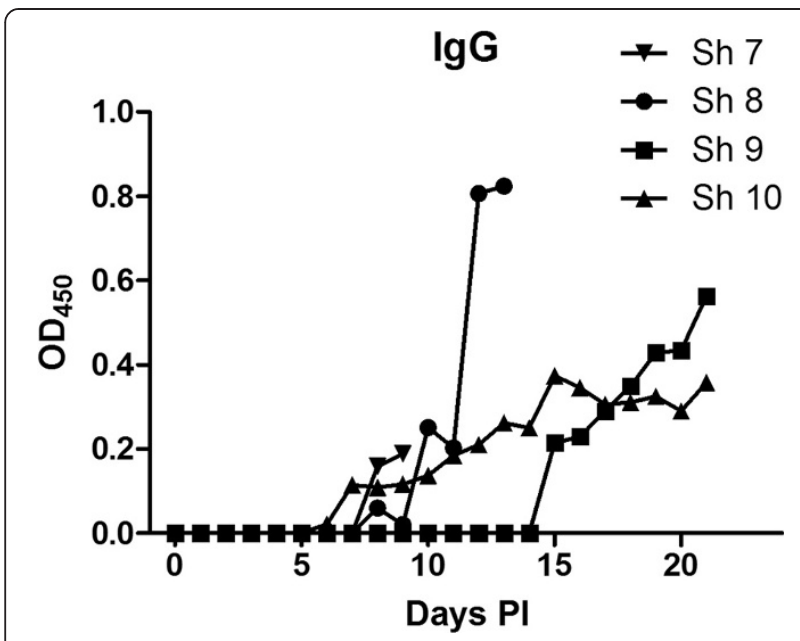

Figure $1 \mathrm{lgG}$ response of the sheep in TLA ELISA in function of time.

namely 12 and 15 dpi. The two sham infected control sheep did not show T. gondii-specific antibodies in IFAT, nor in ELISA.

\section{Interferon-gamma and interleukin-12 cytokine response}

At euthanasia, MCs were isolated from blood, Peyer s patches, MLN, popliteal lymph nodes and spleen and restimulated with rGRA7, rEC2, rMIC3 and total lysate antigen (TLA) to determine the antigen-specific IFNgamma and/or IL-12 responses.

At 4 dpi, TLA, EC2 and MIC3 consistently induced high IFN-gamma concentrations in the MLN cultures of all 3 animals, with the highest responses against MIC3 (DMLN: 80,637 $\mathrm{ng} / \mathrm{ml}$ (mean) 61,951 (SEM); JMLN: 1,313,771 ng/ml 735,659; IMLN: 2,963,760 ng/ml 2,275,224), followed by EC2 (DMLN: 5,400 ng/ml 2,204; JMLN: 129,964 ng/ml 119,802; IMLN: 298,194 ng/ml 155.314) and TLA (Figure 2). In contrast, GRA7 less consistently induced IFN-gamma (Figure 2): 2 out of 3 animals showed IFN-gamma production in jejunal and ileal MLN and 1 out of 3 in duodenal MLN. IFN-gamma was also induced in popliteal LN and spleen, but mainly by MIC3 and to a lesser extent by TLA. Responses in PP and PBMC were absent.

At 8 and $10 \mathrm{dpi}$, the IFN-gamma pattern was completely different with mostly low or no responses in MLN, but responses more localized in PP, PBMC and popliteal LN with the highest concentrations following TLA stimulation and lower responses following GRA7 stimulation. Neither EC2, MIC3 nor TLA induced IFNgamma responses in the MLN cell cultures. Only GRA7 induced IFN-gamma in MLN of all 4 animals with the lower concentrations at $8 \mathrm{dpi}$ (Figure 2). GRA7 also induced IFN-gamma production in popliteal LN cell cultures of 3 out of 4 animals, and in PBMC and spleen cell cultures in 2 out of 4 animals, but it did not induce IFNgamma in PP cell cultures. Only TLA induced IFNgamma in PP cell cultures of all 3 small intestinal sites in 2 out of 4 animals. The same 2 animals showed TLAinduced IFN-gamma in popliteal LN and PBMC cultures. At 14 and $21 \mathrm{dpi}$, the IFN-gamma response was also pronounced in the MLN and to a lesser extent in the spleen, with mainly MIC3 inducing good responses in MLN, whereas especially TLA gave high responses in the spleen. TLA and GRA7 induced-responses were absent in PP, popliteal LN and PBMC cultures, whereas low TLA induced-responses could be seen in spleen cell cultures of 3 on 4 animals (one sheep euthanatized at $14 \mathrm{dpi}$ and 2 at $21 \mathrm{dpi}$ ) and low MIC3 and EC2-induced-responses in 2 on 4 animals (at $21 \mathrm{dpi}$ ). All 4 animals showed IFN-gamma responses induced by TLA, EC2, MIC3 and GRA7 in at least one of their MLN cultures, but responses were lower than those seen at $4 \mathrm{dpi}$. There was no IFN-gamma induced in the MCs of the control animal.

Comparable to IFN-gamma, IL-12 production at day 4 was most consistently induced in the MLN cell cultures (Figure 3). However, whereas GRA7 was the weakest inducer of IFN-gamma, in JMLN it was the best inducer of IL-12 $(0.50 \mathrm{u} / \mathrm{ml} 0.16(\mathrm{SEM}))$, followed by EC2 $(0.29$ $\mathrm{u} / \mathrm{ml} 0.07$ (SEM)), MIC3 (0.26 u/ml 0.06 (SEM)) and TLA $(0.06 \mathrm{u} / \mathrm{ml} 0.02(\mathrm{SEM}))$. The latter induced low amounts of IL-12 in DMLN of one animal and in JMLN of another animal. Besides, low amounts of IL-12 were induced by MIC3 in PP of two animals, by TLA in the $\mathrm{PP}$ of the third animal and by EC2 in the popliteal LN of one animal.

At 8 and $10 \mathrm{dpi}$, the responses of MLN were overall lower except for one animal in which TLA induced 7.4 $\mathrm{u} / \mathrm{ml}$ in jejunal MLN and EC2 $10.1 \mathrm{u} / \mathrm{ml}$ in ileal MLN. Neither of the antigens consistently induced IL-12 responses in the MLN cell cultures, but in each animal at least one antigen induced IL-12 in at least one of the MLN cell cultures (Figure 3). The same was seen for the PP cell cultures. In popliteal LN cell cultures and spleen, two of the 4 animals showed IL-12 production following restimulation with different antigens. PBMCs remained IL-12 negative. So at these time points more variation was seen in the IL-12 response than in the IFN-gamma response.

At 14 dpi, EC2 induced IL-12 in cell cultures of all tissues except of spleen, with high concentrations in duodenal MLN $(40.9 \mathrm{u} / \mathrm{ml})$ and extremely high concentrations in popliteal LN cell cultures $(635,62 \mathrm{u} / \mathrm{ml})$. None of the other antigens induced IL-12 in MLN cell cultures (Figure 3). For the PP, GRA7 and MIC3 induced IL-12 in duodenal, EC2 in jejunal and MIC3 and TLA in ileal PP cell cultures. Besides EC2, TLA induced also high IL-12 concentrations in the popliteal $\mathrm{LN}$ cell cultures $(32.8 \mathrm{u} / \mathrm{ml})$. MIC3, GRA7 and TLA induced IL-12 in PBMCs and 


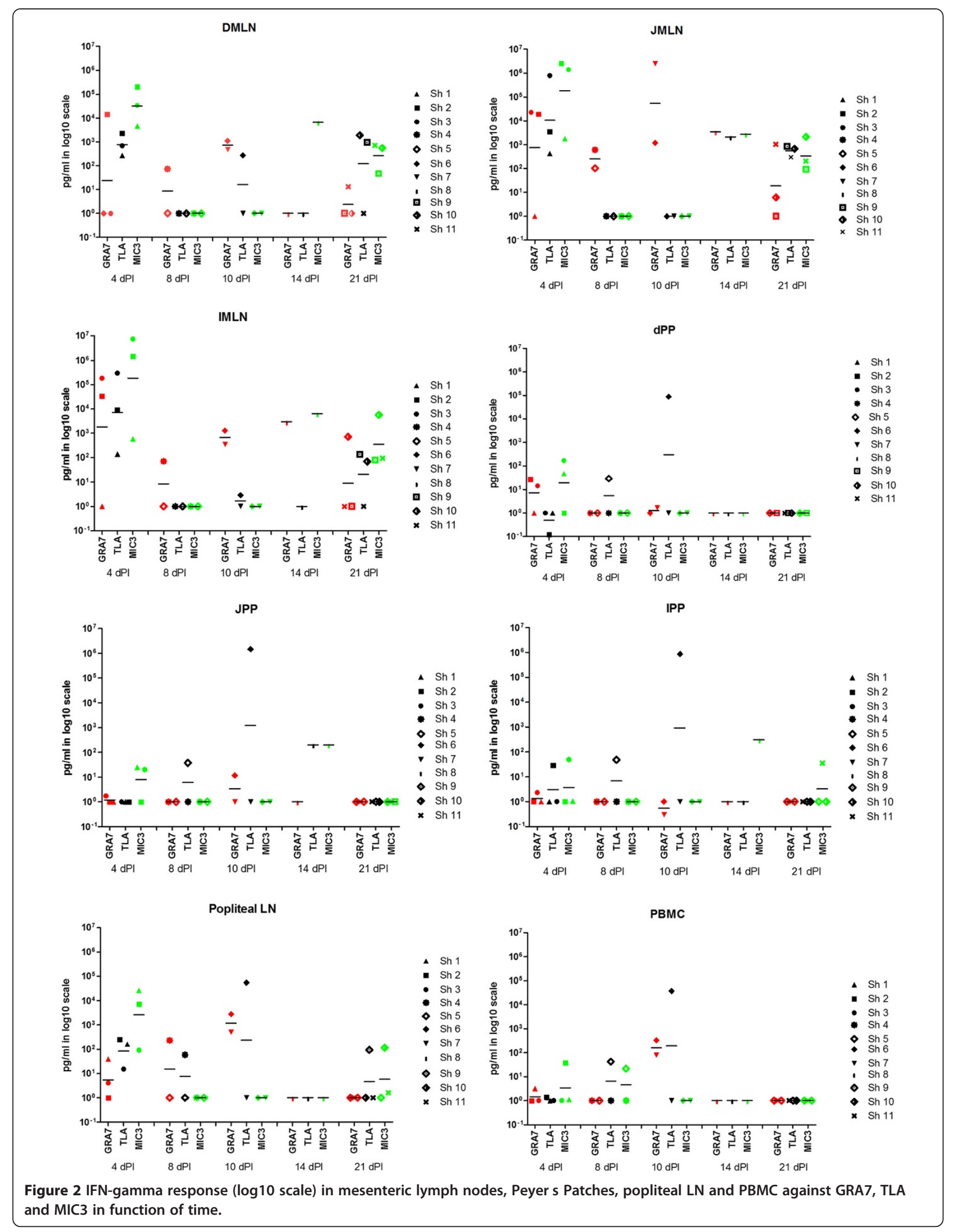



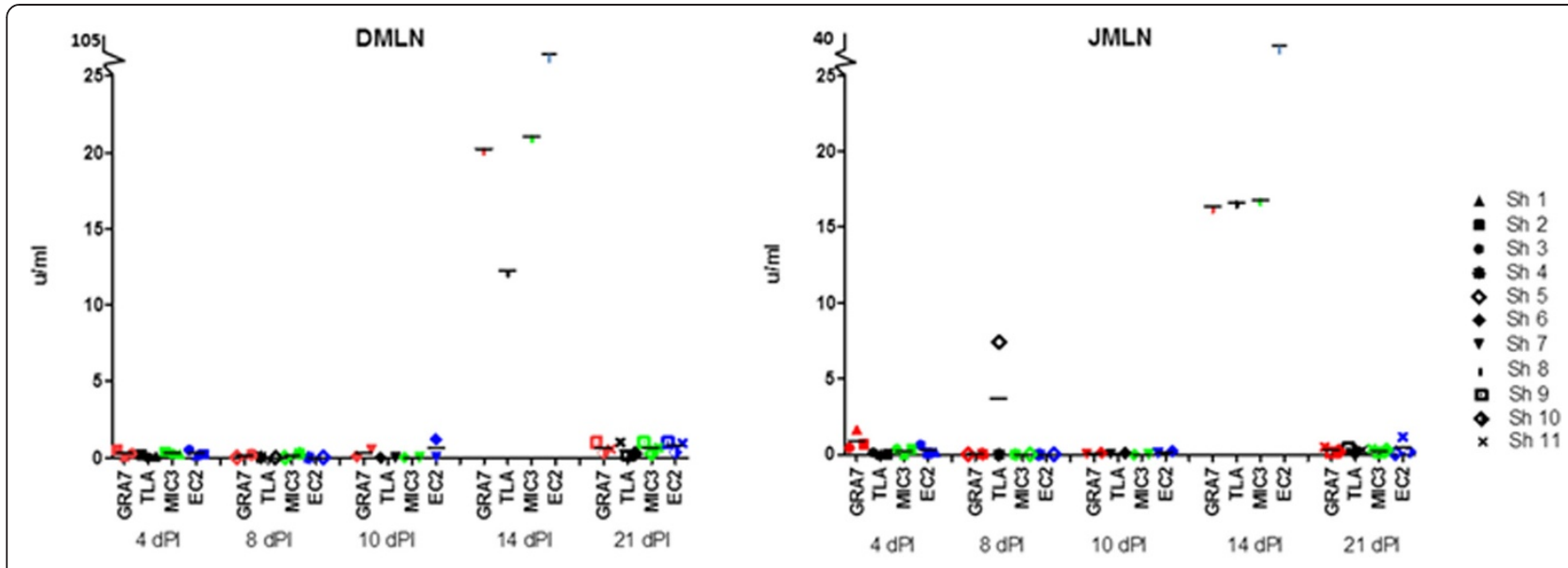

IMLN

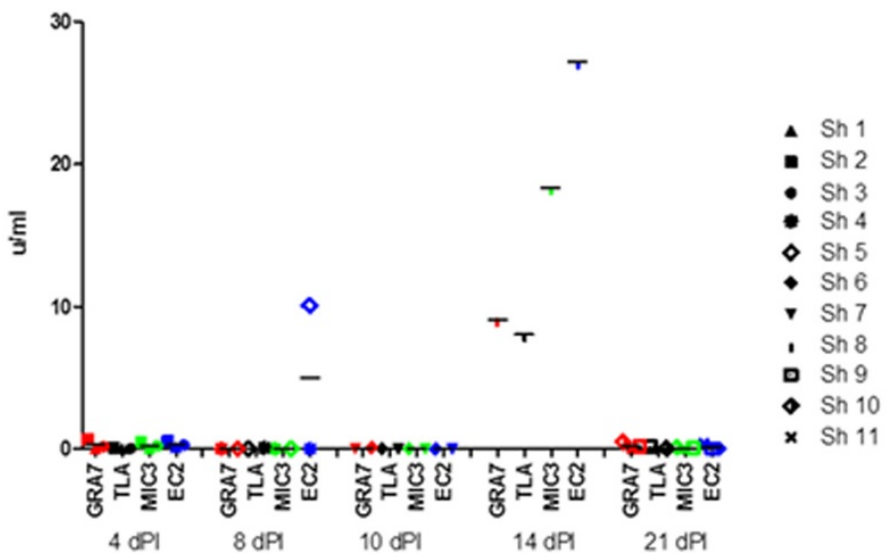

Figure 3 IL-12 response $(\mathrm{u} / \mathrm{ml})$ in mesenteric lymph nodes against GRA7, TLA, MIC3 and EC2 in function of time.

splenocytes $(1.74 \quad 6.08 \mathrm{u} / \mathrm{ml})$. So, especially the IL-12 response in popliteal LN and PBMCs was a noteworthy difference with the IFN-gamma response.

At $21 \mathrm{dpi}$, the IL-12 response was absent in popliteal $\mathrm{LN}$ and PBMCs, was present in the splenocytes culture of one animal stimulated with EC2 and MIC3 and was consistently present in low concentration in duodenal and jejunal MLN cultures stimulated with the recombinant antigens and TLA (Figure 3). It was less consistently present in ileal MLN cultures, similar to the IFN-gamma response.

\section{Discussion}

$T$. gondii seropositive sheep are probably latently infected for life and harbor tissue cysts in various tissues. Therefore, the consumption of un- or undercooked meat from seropositive animals is a high risk for humans [2]. In the present study a type II strain was used for experimental infection of sheep since type II strains are most commonly found in animals in Europe and are most commonly identified as a cause of human toxoplasmosis world-wide [40]. A live intramuscular vaccine (Toxovax,
MSD Animal Health) that is on the market can prevent congenital toxoplasmosis in sheep. However, no current vaccine can prevent infection, suggesting that new vaccination strategies are needed. Since $T$. gondii infection of sheep mostly occurs via the oral route, inducing mucosal protection against the infection might be important. Therefore insights are needed in the acute events in the small intestine following oral infection $[8,41]$. Whereas several natural and experimental $T$. gondii infections have been performed in sheep, none focused in the same detail on the initial phase of the infection at the intestinal mucosa and lymphoid tissues and its local cytokine response as our study did [2,7,21,42-45].

In our study, sheep were orally infected with 3000 tissue cysts. Because infectious oocysts are more difficult to obtain in sufficient quantities, lead to environmental contamination and are a serious risk for laboratory personnel, tissue cysts where used even though oral infection in sheep mostly occurs via ingestion of oocysts during grazing [46]. Nevertheless infection with tissue cysts can occur, although rare, when sheep eat the placenta or abortion products from ewes that aborted as a 
result of toxoplasmosis [47-49]. As mentioned above, only a few studies analyzed the immune response in sheep, three of them after oral inoculation with oocysts $[42,45,50]$ and four following an intraperitoneal injection with tachyzoites of the RH strain or S48 strain [17,51-53]. The latter is a non-natural infection. One other study analyzed the immune after a subcutaneous infection with tissue cysts, a non-natural infection route [54].

T. gondii tachyzoites preferentially entered the cranial small intestine around $4 \mathrm{dpi}$. Most likely, infection occurs at the same site when oocysts are given orally. Indeed, Dubey and Sharma [55] found that excystation of oocysts and the release of sporozoites takes place in the small intestine.

Since parasites were detected simultaneously in epithelial cells, lamina propria, MLN and blood in one sheep at $4 \mathrm{dpi}$, our findings suggest that some parasites most likely directly pass the epithelial barrier to reach MLN and blood. This early detection of parasite DNA in blood could be a consequence of the use of tissue cysts for oral infection, which might pass the epithelial layer more early than when infection occurs with oocysts, since Dubey and Sharma [55] detected parasitaemia between 6 and 11 days after orally inoculating sheep with oocysts [55]. Four days after infection, sheep were still IgM and IgG seronegative in IFA and IgG negative in TLA ELISA. However, stimulation of mesenteric lymphocytes and splenocytes from animals infected 4 days earlier induced a significantly higher IFN-gamma response than when tested later. The response at day 4 is too early to be the result of antigen-specific CD4+ and/or CD8+ T lymphocytes. A T-cell independent IFN-gamma production by NK-cells [56] and CD4+ T cells [57] has been described in mice and is dependent on the production of IL-12 and tumor necrosis factor-alfa (TNF-alfa) by macrophages [58]. In the present study, a generalized but low IL-12 production was measured in the MLN cultures at 4 dpi. During this early infection stage, the parasite triggers several components of the innate immune system. Macrophages, NK cells, dendritic cells as well as neutrophils release cytokines such as IL-12 and IFN-gamma as a result of the infection. This early produced IFNgamma is most likely crucial for inducing resistance against the parasite $[59,60]$. Previous mouse studies have demonstrated that IL-12 production is critical to induce IFN-gamma production and protection against $T$. gondii. Indeed, in IL-12p35/p40 knockout mice, IFN-gamma levels were severely decreased and Toxoplasma gondii tachyzoites underwent uncontrolled replication, which most likely caused early death of the IL-12 deficient mice [61]. While triggering the innate immune system, parasite antigens are also taken up and presented by antigen-presenting cells, leading to a parasite-specific T-cell immunity [62].
At 8 dpi, parasite DNA was highly present in the tissues of the cranial small intestine and MLN and this remained so until $14 \mathrm{dpi}$, suggesting replication of the parasite in the small intestinal mucosa, mucosa-associated lymphoid tissues and associated draining lymph nodes. This is consistent with the observations of Dubey and Sharma [55] who found tachyzoites in the mesenteric lymph nodes of sheep from $7 \mathrm{dpi}$ onwards. Also in mice an increase in parasite burden occurs in PP, MLN, IE and LP between 4 and 9 dpi [63]. Specific IgM and IgG antibodies appeared almost simultaneously $9 \mathrm{dpi}$. Specific antibodies in the presence of complement can lyse and therefore clear extracellular tachyzoites [59]. Parallel with the appearance of antibodies, a significant decrease in the IFN-gamma response and a decrease in the IL-12 response were observed. Different antigens induced IL-12 in different gut tissues of different sheep. This was not the case for IFN-gamma. GRA7 quite consistently induced IFN-gamma in MLN lymphocyte cultures of the four animals tested at 8 and 10 dpi, whereas TLA clearly induced IFN-gamma in the PP lymphocyte culture of two of the four euthanized animals. This suggests that different antigens were involved in the induction of the IFN-gamma responses in PP versus MLN. Homing of the activated T cells from both lymphoid tissues to other sites could explain why both antigen preparations induced responses in PBMC and popliteal LN cell cultures. Such homing at $8 \mathrm{dpi}$ is consistent with the increase of IFN-gamma producing CD4+ lymphocytes in efferent lymph of surgically cannulated experimentally infected lymph nodes at $11 \mathrm{dpi}$ [52]. Our results suggest that a $\mathrm{T}$ cell independent response becomes replaced by an antigen-specific $\mathrm{T}$ lymphocyte response around $8 \mathrm{dpi}$. That several antigens induced IFN-gamma and IL-12 responses in popliteal lymph nodes and spleen cell cultures, distant systemic lymphoid tissues, supports for systemic migration of the parasite.

Our observation that the parasite DNA disappears from the small intestine, popliteal LN and PBMC and spleen 3 weeks after infection, indicates that the parasite load drops below the detection limit of the PCR. Indeed, a negative result in PCR does not imply that these tissues are completely free of parasite DNA. However, that most of the tested tissues became PCR negative could be an indication that the parasite is either suppressed in these tissues, cleared from these tissues or otherwise is leaving these tissues between 2 and 3 weeks post infection. This coincided with the significant increase of IgG antibodies between 9 and $21 \mathrm{dpi}$.

In previous studies, the immune response was studied following oral inoculation with oocysts or following intraperitoneal injection with tachyzoites of the $\mathrm{RH}$ strain $[64,65]$. Whereas antibodies were detectable $14 \mathrm{dpi}$ following oral inoculation with 5000 or 50.000 oocysts [64], they were only detected 1 month post inoculation following 
intraperitoneal injection with tachyzoites [65]. In our study the oral inoculation with tissue cysts resulted in a more rapid antibody response. However, this response was similar to the one observed by McColgan et al. [54], which saw IgG appear nine days after experimental infection with tissue cysts [54]. This again supports the hypothesis that the parasite passes the intestinal epithelial barrier more quickly after an oral infection with tissue cysts, although it can not be excluded that the earlier response was a result of strain differences $[8,14,55]$.

While the antibody response increased, and the parasite seems to disappear from systemic lymphoid tissues, also the IL-12 response in these tissues decreased or became absent. This coincided with a decreased or negative antigen-specific IFN-gamma response in PP, PBMC and popliteal LN cell cultures. Interestingly, these observations are in accordance with findings of Innes et al. $[17,52]$ who infected sheep subcutaneously with tachyzoites. They could not detect IFN-gamma anymore in the lymph flow from lymph nodes draining the subcutaneous region from 11 days after infection onwards. At that time they noticed a switch from predominantly $\mathrm{CD}^{+}$proliferating lymphocytes to $\mathrm{CD}^{+}$proliferating lymphocytes. In our study, antigen-specific IFN-gamma responses were still present in MLN and spleen cell cultures 21 dpi. Since MLN not only drain the gut but also systemic sites such as the peritoneal cavity and since the spleen is the secondary lymphoid organ draining the blood both responses could play a role in controlling a systemic infection occurring at this stage [52].

\section{Conclusions}

Our results indicate that parasites enter the cranial small intestine the first days after infection. Three weeks later T. gondii DNA could not be recovered anymore from the intestine. This coincided with the increase of IgG1 and IgG2 antibodies and a decrease of the antigenspecific IFN-gamma response in PP, PBMC and popliteal LN. Furthermore, the experiments support a collaborate role of humoral and cellular immunity in acute $T$. gondii infections in sheep.

\section{Competing interests}

The authors declare that they have no competing interests.

\section{Authors contributions}

DV performed the experiments and wrote the initial manuscript and. SD coordinated the experiments and helped with the detection of parasite load by real-time PCR. GE provided the recombinant ovine IFN-gamma and recombinant IL-12 and helped with the cytokine-ELISA. PD contributed to final manuscript. EC coordinated the experiments and made the revisions required for submission of the final manuscript. All authors read and approved the final manuscript.

\section{Acknowledgements}

The work described herein was funded by the Institute for the Promotion of Innovation through Science and Technology in Flanders (IWT-Vlaanderen) and the Federal Public Service, Health, Food Chain Safety and Environment.
GE is funded by the Scottish Government Rural and Environmental Science and Analytical Services Division (RESAS) and supported by the European Community s Seventh Framework Programme (FP7, 2007 2013), Research Infrastructures action, under the grant agreement No. FP7-228394 (NADIR).

\section{Author details}

'Laboratory of Immunology, Faculty of Veterinary Medicine, Ghent University, Ghent, Belgium. ${ }^{2}$ National Reference Laboratory for Toxoplasmosis, Operational Direction Communicable and Infectious Diseases, Scientific Institute of Public Health, Brussels, Belgium. ${ }^{3}$ Moredun Research Institute, Pentlands Science Park, Bush Loan, Midlothian, Penicuik EH26 OPZ, Scotland, UK. ${ }^{4}$ Department of Biomedical Sciences, Institute of Tropical Medicine, Antwerp, Belgium. ${ }^{5}$ Laboratory of Parasitology, Faculty of Veterinary Medicine, Ghent University, Ghent, Belgium.

Received: 27 May 2014 Accepted: 2 December 2014

Published online: 16 December 2014

\section{References}

1. Cenci-Goga BT, Rossitto PV, Sechi P, McCrindle CM, Cullor JS: Toxoplasma in animals, food, and humans: an old parasite of new concern. Foodborne Pathog Dis 2011, 8:751 762.

2. Buxton D, Maley SW, Wright SE, Rodger S, Bartley P, Innes EA: Toxoplasma gondii and ovine toxoplasmosis: new aspects of an old story. Vet Parasitol 2007, 149:25 28.

3. EFSA, 2007. Scientific opinion of the panel on Biological Hazards and Animal Health Animal Welfare on a request from the European Food Safety Authority (self mandate) to issue a scientific opinion on the review of the Community Summary Report on Trends and Sources of Zoonoses, Zoonotic Agents and Antimicrobial Resistance in the European Union in 2005. EFSA J 132 (http://www.efsa.europa.eu/en/ scdocs/doc/600.pdf)

4. VIDA: Veterinary Investigation Surveillance Report. 2009

5. Cook AJ, Gilbert RE, Buffolano W, Zufferey J, Petersen E, Jenum PA, Foulon W, Semprini AE, Dunn DT: Sources of toxoplasma infection in pregnant women: European multicentre case control study. European Research Network on Congenital Toxoplasmosis. BMJ 2000, 321:142 147.

6. Dubey JP, Beattie CP: Toxoplasmosis of Animals and Man. Boca Raton, FL 33431, USA: CRC Press, Inc; 1988:220.

7. Innes EA, Bartley PM, Maley S, Katzer F, Buxton D: Veterinary vaccines against Toxoplasma gondii. Mem Inst Oswaldo Cruz 2009, 104:246 251.

8. Esteban-Redondo I, Innes EA: Toxoplasma gondii infection in sheep and cattle. Comp Immunol Microbiol Infect Dis 1997, 20:191 196.

9. Pappas G, Roussos N, Falagas ME: Toxoplasmosis snapshots: global status of Toxoplasma gondii seroprevalence and implications for pregnancy and congenital toxoplasmosis. Int J Parasito/ 2009, 39:1385 1394.

10. Rodger SM, Maley SW, Wright SE, Mackellar A, Wesley F, Sales J, Buxton D: Role of endogenous transplacental transmission in toxoplasmosis in sheep. Vet Rec 2006, 159:768 772.

11. Buxton D: Protozoan infections (Toxoplasma gondii, Neospora caninum and Sarcocystis spp.) in sheep and goats: recent advances. Vet Res 1998, 29:289 310 .

12. Morley EK, Williams RH, Hughes JM, Terry RS, Duncanson P, Smith JE, Hide G: Significant familial differences in the frequency of abortion and Toxoplasma gondii infection within a flock of Charollais sheep. Parasitology 2005, 131:181 185.

13. Morley EK, Williams RH, Hughes JM, Thomasson D, Terry RS, Duncanson $P$, Smith JE, Hide G: Evidence that primary infection of Charollais sheep with Toxoplasma gondii may not prevent foetal infection and abortion in subsequent lambings. Parasitology 2008, 135:169 173.

14. Dubey JP: Toxoplasmosis in sheep the last 20 years. Vet Parasitol 2009, 163:1 14.

15. Williams RH, Morley EK, Hughes JM, Duncanson P, Terry RS, Smith JE, Hide G: High levels of congenital transmission of Toxoplasma gondii in longitudinal and cross-sectional studies on sheep farms provides evidence of vertical transmission in ovine hosts. Parasitology 2005, 130:301 307.

16. Innes EA, Bartley PM, Buxton D, Katzer F: Ovine toxoplasmosis. Parasitology 2009, 136:1887 1894.

17. Innes EA, Panton WR, Thomson KM, Maley S, Buxton D: Kinetics of interferon gamma production in vivo during infection with the $S 48$ vaccine strain of Toxoplasma gondii. J Comp Pathol 1995, 113:89 94. 
18. Innes EA, Vermeulen AN: Vaccination as a control strategy against the coccidial parasites Eimeria, toxoplasma and neospora. Parasitology 2006, 133(Suppl):S145 S168.

19. Blewett DA, Miller JK, Buxton D: Response of immune and susceptible ewes to infection with Toxoplasma gondii. Vet Rec 1982, 111:175 178.

20. Blewett DA, Watson WA: The epidemiology of ovine toxoplasmosis. II. possible sources of infection in outbreaks of clinical disease. Br Vet J 1983, 139:546 555

21. Buxton D, Maley SW, Wright SE, Rodger S, Bartley P, Innes EA: Ovine toxoplasmosis: transmission, clinical outcome and control. Parassitologia 2007, 49:219 221.

22. Hunter CA, Subauste CS, Remington JS: The role of cytokines in toxoplasmosis. Biotherapy 1994, 7:237 247.

23. Torres-Morales E, Taborda L, Cardona N, De-la-Torre A, Sepulveda-Arias JC, Patarroyo MA, Gomez-Marin JE: Th1 and Th2 immune response to P30 and ROP18 peptides in human toxoplasmosis. Med Microbiol Immunol 2014, 203(5):315 321.

24. Bivas-Benita M, Laloup M, Versteyhe S, Dewit J, De Braekeleer J, Jongert E, Borchard G: Generation of Toxoplasma gondii GRA1 protein and DNA vaccine loaded chitosan particles: preparation, characterization, and preliminary in vivo studies. Int J Pharm 2003, 266:17 27.

25. Martrou P, Pestre M, Loubet R, Nicolas A, Malinvaud G: La toxoplasmose congnitale (note concernant un cas mortel). Limousin Med 1965, 53:3 7 .

26. Verhelst D, De Craeye S, Dorny P, Melkebeek V, Goddeeris B, Cox E, Jongert E: IFN-gamma expression and infectivity of Toxoplasma infected tissues are associated with an antibody response against GRA7 in experimentally infected pigs. Vet Parasitol 2011, 179:14 21.

27. Aubert D, Maine GT, Villena I, Hunt JC, Howard L, Sheu M, Brojanac S, Chovan LE, Nowlan SF, Pinon JM: Recombinant antigens to detect Toxoplasma gondii-specific immunoglobulin $\mathrm{G}$ and immunoglobulin $\mathrm{M}$ in human sera by enzyme immunoassay. J Clin Microbiol 2000, 38:1144 1150

28. Bonhomme A, Maine GT, Beorchia A, Burlet H, Aubert D, Villena I, Hunt J, Chovan L, Howard L, Brojanac S, Sheu M, Tyner J, Pluot M, Pinon JM: Quantitative immunolocalization of a P29 protein (GRA7), a new antigen of toxoplasma gondii. J Histochem Cytochem 1998, 46:1411 1422.

29. Jacobs D, Vercammen M, Saman E: Evaluation of recombinant dense granule antigen 7 (GRA7) of Toxoplasma gondii for detection of immunoglobulin $\mathrm{G}$ antibodies and analysis of a major antigenic domain. Clin Diagn Lab Immunol 1999, 6:24 29.

30. Holec-Gasior L: Toxoplasma gondii recombinant antigens as tools for serodiagnosis of human toxoplasmosis: current status of studies. Clin Vaccine Immunol 2013, 20:1343 1351

31. Fischer HG, Stachelhaus S, Sahm M, Meyer HE, Reichmann G: GRA7, an excretory $29 \mathrm{kDa}$ Toxoplasma gondii dense granule antigen released by infected host cells. Mol Biochem Parasitol 1998, 91:251 262.

32. Jongert E, Verhelst D, Abady M, Petersen E, Gargano N: Protective Th1 immune responses against chronic toxoplasmosis induced by a protein-protein vaccine combination but not by its DNA-protein counterpart. Vaccine 2008, 26:5289 5295.

33. Vercammen M, Scorza T, Huygen K, De Braekeleer J, Diet R, Jacobs D, Saman $E$, Verschueren $H$ : DNA vaccination with genes encoding Toxoplasma gondii antigens GRA1, GRA7, and ROP2 induces partially protective immunity against lethal challenge in mice. Infect Immun 2000 68:38 45

34. Vandenbroeck K, Nauwynck H, Vanderpooten A, Van Reeth K, Goddeeris B, Billiau A: Recombinant porcine IFN-gamma potentiates the secondary $\lg \mathrm{G}$ and $\lg \mathrm{A}$ responses to an inactivated suid herpesvirus- 1 vaccine and reduces postchallenge weight loss and fever in pigs. $J$ Interferon Cytokine Res 1998, 18:739 744 .

35. Vande Walle K, De Zutter L, Cox E: Oral infection with a Shiga toxinnegative Escherichia coli 0157:H7 strain elicits humoral and cellular responses but does not protect sheep from colonisation with the homologous strain. Vet Microbiol 2011, 148:317 322

36. James GT: Inactivation of the protease inhibitor phenylmethylsulfonyl fluoride in buffers. Anal Biochem 1978, 86:574 579.

37. Kijlstra A, Meerburg B, Cornelissen J, De Craeye S, Vereijken P, Jongert E: The role of rodents and shrews in the transmission of Toxoplasma gondii to pigs. Vet Parasitol 2008, 156:183 190.

38. Cardoso LS, Araujo MI, Goes AM, Pacifico LG, Oliveira RR, Oliveira SC: Polymyxin B as inhibitor of LPS contamination of Schistosoma mansoni recombinant proteins in human cytokine analysis. Microb Cell Fact 2007, 6:1.
39. Hope JC, Kwong LS, Thom M, Sopp P, Mwangi W, Brown WC, Palmer GH, Wattegedera S, Entrican G, Howard CJ: Development of detection methods for ruminant interleukin (IL)-4. J Immunol Methods 2005, 301:114 123.

40. Sibley LD, Khan A, Ajioka JW, Rosenthal BM: Genetic diversity of Toxoplasma gondii in animals and humans. Philos Trans R Soc Lond B Biol Sci 2009, 364:2749 2761.

41. Tenter AM, Heckeroth AR, Weiss LM: Toxoplasma gondii: from animals to humans. Int J Parasitol 2000, 30:1217 1258.

42. Benavides J, Maley S, Pang Y, Palarea J, Eaton S, Katzer F, Innes EA, Buxton D, Chianini F: Development of lesions and tissue distribution of parasite in lambs orally infected with sporulated oocysts of Toxoplasma gondii. Vet Parasitol 2011, 179:209 215.

43. Dubey JP: History of the discovery of the life cycle of Toxoplasma gondii. Int J Parasitol 2009, 39:877 882

44. Falcon J, Freyre A: Toxoplasma gondii: prototype immunization of lambs against formation of muscle and brain cysts. Vet Parasitol 2009, 166:15 20.

45. Gutierrez J, O Donovan J, Williams E, Proctor A, Brady C, Marques PX, Worrall S, Nally JE, McElroy M, Bassett H, Sammin D, Buxton D, Maley S, Markey BK: Detection and quantification of Toxoplasma gondii in ovine maternal and foetal tissues from experimentally infected pregnant ewes using real-time PCR. Vet Parasitol 2010, 172:8 15

46. Race $R$, Jenny A, Sutton D: Scrapie infectivity and proteinase K-resistant prion protein in sheep placenta, brain, spleen, and lymph node: implications for transmission and antemortem diagnosis. J Infect Dis 1998, 178:949 953.

47. Abu-Dalbouh MA, Ababneh MM, Giadinis ND, Lafi SQ: Ovine and caprine toxoplasmosis (Toxoplasma gondii) in aborted animals in Jordanian goat and sheep flocks. Trop Anim Health Prod 2012, 44:49 54.

48. Dubey JP: Toxoplasma gondii cysts in placentas of experimentally infected sheep. Am J Vet Res 1987, 48:352 353.

49. Riyadh R: Flock Level Sero-Prevalence of and Risk Factors for Toxoplasma Gondii in Sheep and Goats in Northern Jordan, Unpublished Master s thesis. Irbid, Jordan: Jordan University of Science and Technology; 2005.

50. Coughlan SN, Saman E, Jacobs D, Mercier C, Cesbron-Delauw MF, Trees AJ: Cellular and humoral immune responses to recombinant antigens in sheep infected with Toxoplasma gondii. Parasite Immunol 1995, 17:465 468

51. Buxton D, Thomson KM, Maley S, Wastling JM, Innes EA, Panton WR, Nicoll S: Primary and secondary responses of the ovine lymph node to Toxoplasma gondii: cell output in efferent lymph and parasite detection. J Comp Pathol 1994, 111:231 241

52. Innes EA, Panton WR, Sanderson A, Thomson KM, Wastling JM, Maley S, Buxton D: Induction of CD4+ and CD8+ T cell responses in efferent lymph responding to Toxoplasma gondii infection: analysis of phenotype and function. Parasite Immunol 1995, 17:151 160.

53. Wastling JM, Nicoll S, Buxton D: Comparison of two gene amplification methods for the detection of Toxoplasma gondii in experimentally infected sheep. J Med Microbiol 1993, 38:360 365.

54. McColgan C, Buxton D, Miller HR: Studies on ovine efferent lymph following infection with Toxoplasma gondii. J Comp Pathol 1987, 97:695 703

55. Dubey JP, Sharma SP: Parasitemia and tissue infection in sheep fed Toxoplasma gondii oocysts. J Parasitol 1980, 66:111 114

56. Sher A, Oswald IP, Hieny S, Gazzinelli RT: Toxoplasma gondii induces a T-independent IFN-gamma response in natural killer cells that requires both adherent accessory cells and tumor necrosis factor-alpha. J Immunol 1993, 150:3982 3989.

57. Gazzinelli RT, Hakim FT, Hieny S, Shearer GM, Sher A: Synergistic role of CD4+ and CD8+ T lymphocytes in IFN-gamma production and protective immunity induced by an attenuated Toxoplasma gondii vaccine. J Immunol 1991, 146:286 292.

58. Gazzinelli RT, Denkers EY, Sher A: Host resistance to Toxoplasma gondii: model for studying the selective induction of cell-mediated immunity by intracellular parasites. Infect Agents Dis 1993, 2:139 149.

59. Bhopale GM: Development of a vaccine for toxoplasmosis: current status. Microbes Infect 2003, 5:457 462.

60. Gazzinelli RT, Wysocka M, Hayashi S, Denkers EY, Hieny S, Caspar P, Trinchieri G, Sher A: Parasite-induced IL-12 stimulates early IFN-gamma synthesis and resistance during acute infection with Toxoplasma gondii. J Immunol 1994, 153:2533 2543.

61. Vossenkamper A, Struck D, Alvarado-Esquivel C, Went T, Takeda K, Akira S, Pfeffer K, Alber G, Lochner M, Forster I, Liesenfeld O: Both IL-12 and IL-18 
contribute to small intestinal Th1-type immunopathology following oral infection with Toxoplasma gondii, but IL-12 is dominant over IL-18 in parasite control. Eur J Immunol 2004, 34:3197 3207.

62. Denkers EY, Gazzinelli RT: Regulation and function of T-cell-mediated immunity during Toxoplasma gondii infection. Clin Microbiol Rev 1998, 11:569 588

63. Morampudi V, De Craeye S, Le Moine A, Detienne S, Braun MY, D Souza S: Partial depletion of CD4(+)CD25(+)Foxp3(+) T regulatory cells significantly increases morbidity during acute phase Toxoplasma gondii infection in resistant BALB/c mice. Microbes Infect 2011, 13:394 404.

64. Tenter AM, Vietmeyer $C$, Johnson AM: Development of ELISAs based on recombinant antigens for the detection of Toxoplasma gondii-specific antibodies in sheep and cats. Vet Parasitol 1992, 43:189 201.

65. Verma SP, Bhardwaj RM, Gautam OP: Application of countercurrent immunoelectrophoresis (CIEP) in the sero-diagnosis of Toxoplasma antibodies in sheep. J Vet Parasitol 1989, 3:61 62.

doi:10.1186/s12917-014-0293-5

Cite this article as: Verhelst et al: Parasite distribution and associated immune response during the acute phase of Toxoplasma gondii infection in sheep. BMC Veterinary Research 2014 10:293.

\section{Submit your next manuscript to BioMed Central and take full advantage of:}

$\bowtie$ Convenient online submission

$\otimes$ Thorough peer review

$\nabla$ No space constraints or color $\nabla$ gure charges

$\otimes$ Immediate publication on acceptance

\Inclusion in PubMed, CAS, Scopus and Google Scholar

$\otimes$ Research which is freely available for redistribution 